\title{
Genital prevalence of HPV types and co-infection in men
}

Marcos P. Freire, Daniel Pires, Raphael Forjaz, Sérgio Sato, Ismael Cotrim, Mônica Stiepcich, Bruno Scarpellini, José C. Truzzi

Division of Urology, Fleury Group (MPF, IC, MS, BS, JCT); Anhembi Morumbi Medical School (MPF, DP, RF, SS,) and Federal University of São Paulo (MPF, IC, JCT) Sao Paulo, Brazil

\section{ABSTRACT}

Introduction: HPV infection is a highly prevalent sexually transmitted disease and there is evidence of the relationship of HPV infection and the development of genital warts, penile intraepitelial neoplasia, invasive penile carcinoma and cervical cancer. However, there is sparse data regarding the prevalence of HPV types and co-infection of different HPV types among men.

Objectives: To assess the prevalence of HPV subtypes infections and rates of co-infection among men.

Materials and Methods: 366 men were evaluated from March to October 2010. Men were referred to our institution for HPV diagnostic evaluation based on the following criteria: 1 . presence of a genital wart; 2 . presence of an atypical genital lesion; 3 . absence of symptoms and a partner with a HPV diagnosis; 4 . absence of symptoms and a desire to undergo a full STD diagnostic evaluation. Genital samples were collected from the urethra, penile shaft, scrotum and anus with Digene ${ }^{\circledR}$ collection and preservation kit and submitted to HPV genotype microarray detection (Papillocheck ${ }^{\circledR}$ ). All men were tested for the low-risk HPV types 6-11-40-42-43-44 and for the high-risk HPV types 16-18-31-33-35-39-45-51-52-53-56-58-59-66-68-70-73-82.

Results: Of the 366 men, 11 were tested inconclusive and were excluded from the analysis. 256 men (72.1\% of the men from the cohort referred to our institution) tested positive with genotype micro-array detection and 99 tested negative. The most prevalent HPV-subtypes in the studied population were 6, 42, 51 and 16. Co-infection was found in 153 men. Of those, 70 (19.7\%) had a co-infection by 2 types, 37 (10.4\%) by 3 types; 33 men (9.2\%) by 4 types; 8 men (2.2\%) by 5 types; 1 man (0.3\%) by 6 types; 1 man (0.3\%) by 7 types; 2 men (0.6\%) by 8 types and 1 man $(0.3 \%)$ by 9 types.

Conclusion: The most frequent HPV types were 6, 16, 42 and 51. Co-infection was found in 59\% of our patients. This information is vital to drive future public health policies including massive public vaccination campaign.

\section{ARTICLE INFO}

Key words:

DNA Probes, HPV; Infection; Men

Int Braz J Urol. 2014; 40: 67-71

Submitted for publication:

June 25, 2013

Accepted after revision:

September 17, 2013

\section{INTRODUCTION}

Infection by human papillomavirus (HPV) is the cause of several different diseases in men and women $(1,2)$. Anogenital HPV related infection is the most prevalent common viral sexu- ally transmitted infection worldwide (3). The World Health Organization (WHO) estimates that the prevalence of HPV infection is between nine and thirteen percent or about 630 million people (4). In the United States, CDC (Centers for Disease Control) estimates that approximately 26,000 new cancers attributable 
to HPV occurs each year, including 18,000 among females and 8,000 among males (5). Genital warts are more frequently associated to HPV types 6 and 11 whereas HPV 16 and 18 are more commonly associated to cervical cancers.

HPV infection also prevails as the most common viral infection among the Brazilian population. Female HPV genotyping data shows prevalence rates of 57\%, 23\%, 5\%, 4\% and 3\% for HPV genotypes 16, 18, 31, 33 and 56, respectively (6). A recent large epidemiological study demonstrated that among Brazilian men the prevalence of at least one type of HPV was $86.0 \%$, while more than one HPV type, including high and low risk HPV, was identified in 39.5\% of the samples (7). Nevertheless, data on Brazilian HPV infection and disease among males is scarce.

The aim of our study was to describe HPV genotypes prevalence data and to evaluate rates of co-infection with more than one HPV subtype in our male population.

\section{MATERIAL AND METHODS}

\section{Enrollment}

From March to October 2010, 366 men were referred to the Urological Division of Fleury Medicine and Health from private medical offices for evaluation of penile HPV related disease. Mean age was $35.6 \pm 2.6$ years (range 18-81 years). $\mathrm{Pa}-$ tients were enrolled in a prospective manner and underwent genotyping, cytology and peniscopy. The study was approved by the Ethics Committee of Fleury Medicine and Health and informed consent was obtained from each patient.

\section{Inclusion criteria}

Males with age $>18$ years old with active genital warts lesions; males with atypical penile lesions; males with a partner with a genital diagnosis of HPV and asymptomatic individuals willing to have a complete sexual transmitted diseases (STD) evaluation.

\section{Diagnostic Techniques}

After receiving proper information on the diagnostic methods, men were positioned in supine position. First, samples from the penile shaft, glans, balanopreputial sulcus and urethra were collected for cytology.

HPV genotyping materials were collected with a Digene ${ }^{\circledR}$ kit (Digene, USA). Samples were collected from the same sites as cytology examination. For cytology, specimens were preserved using the ThinPrep ${ }^{\circledR}$ (Hologic, USA) collection and preservation solution. HPV genotype microarray detection was performed with Papillocheck ${ }^{\circledR}$ (Greiner Bio One, Germany). All men were tested for the following low-risk (LR) HPV types 6-1140-42-43-44/55 as well as for the following highrisk (HR) HPV types 16-18-31-33-35-39-45-5152-53-56-58-59-66-68-70-73-82.

Co-infection was defined as an infection with two or more HPV types.

All patients underwent peniscopy by a single physician. Acetic acid (5\%) was spread in the genitalia to show small flat lesions. When indicated, biopsies were obtained using local anesthetics (infiltration of lidocaine 2\%). Samples were examined by the Pathology Department.

\section{Statistical analysis}

All clinical data were collected and prospectively input in an Access ${ }^{\circledR}$ database (Microsoft, Redmond, Washington, USA). SPSS ${ }^{\circledR}$ (SPSS Inc., Chicago, Illinois, USA) were used for the statistical analysis.

\section{RESULTS}

From the cohort of men referred to our institution for HPV diagnostic evaluation, 256 men (72.1\%) tested positive with genotype micro-array detection and 99 tested negative. Eleven inconclusive cases were excluded from analysis. So, our final sample for analysis was composed of 355 males at risk for HPV infection.

Overall HPV prevalence was 72.1\%. The HPV prevalence distribution is shown on Table-1. Low risk HPV types represented $52.6 \%$ of our positive tests. Co-infection was found in 153 men, representing 59.7\% of men who tested positive with an overall HPV co-infection prevalence of $43.1 \%$. Of those, 70(19.7\%) had co-infection by 2 types; 37 (10.4\%) by 3 types; 33 men (9.2\%) by 4 
Table 1 - HPV types prevalence.

\begin{tabular}{|c|c|}
\hline HPV type & Prevalence (\%) \\
\hline 6 & 17.7 \\
\hline 42 & 13.8 \\
\hline 51 & 11.0 \\
\hline 16 & 11.8 \\
\hline $44-55$ & 9.0 \\
\hline 39 & 8.7 \\
\hline 53 & 8.7 \\
\hline 56 & 7.6 \\
\hline 31 & 5.6 \\
\hline 59 & 5.9 \\
\hline 68 & 6.8 \\
\hline 52 & 5.9 \\
\hline 66 & 6.5 \\
\hline 11 & 5.9 \\
\hline 40 & 5.6 \\
\hline 43 & 5.4 \\
\hline 33 & 45 \\
\hline 58 & 3.9 \\
\hline 73 & 3.4 \\
\hline 18 & 2.8 \\
\hline 70 & 3.7 \\
\hline 82 & 2.0 \\
\hline 35 & 1.1 \\
\hline 45 & 1.4 \\
\hline
\end{tabular}

types; 8 men (2.2\%) by 5 types; 1 man (0.3\%) by 6 types; 1 man (0.3\%) by 7 types; 2 men $(0.6 \%)$ by 8 types and 1 man (0.3\%) by 9 types.

Overall, at least one high-risk-HPV (HRHPV) type was found in 58\% of the men and in
$81.1 \%$ of the men tested positive. HPV infection was highly prevalent among middle-aged groups (50-59 years old), young adults (30-39 years) and among youth (18-29 years old), respectively 78.8\%, 76.9\% and 76.7\%. HPV infection distribution shows that at least one HR-HPV type infection prevailed in most of men when divided by age (Figure-1). There was no correlation between high or low risk HPV infections and age. Also, we could not identify any preferential distribution of any HPV type and co-infection.

Figure 1 - HPV infection distribution according to age groups.

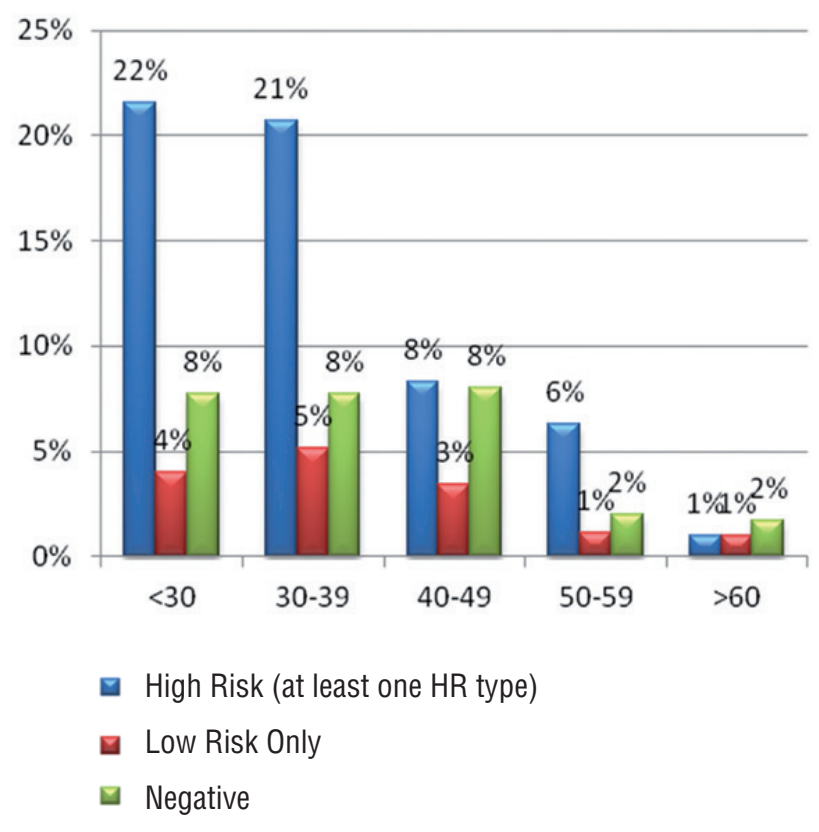

\section{DISCUSSION}

Our study demonstrated some notable findings. At first, this is one of the largest studies on HPV's infection prevalence and its genotype distribution among males.

In this study, HPV was highly prevalent, with $72.1 \%$ of men testing positive for the virus. These results are consonant with previous published data showing prevalence ranging from 1.3 to $72.9 \%(3,8-13)$. Our high number of infected men is probably due to selection, as our sample is 
composed by men already referred for HPV testing with some degree of suspicious. This fact might also be the cause of our high number of at least one high-risk HPV type infection (58\%) among our population. Regarding the observed high prevalence of high-risk HPV types among our studied population, it was also observed by others and may be consequence of the local restrict HPV vaccination policies (14).

In our study, the four more frequent observed HPV types were HPV 6, 42, 51 and 16, representing 54\% of the total amount. This information is consistent with current published data where HPV types 6 and 16 are the most common types observed among men and women $(6,7,15,16)$.

The genotyping description of the HPV infection distribution is an important diagnostic tool once men act as a reservoir for women's infection. Therefore, HPV infection in men greatly affects disease risk in women and must be considered that, in fact, men is less frequently submitted to medical, in special, genital evaluation compared to women $(17,18)$.

Furthermore, the knowledge of HPV prevalence, its subtype and age distribution might guide public health policies and prevention measures, including vaccination. In this regard, a quadrivalent HPV vaccine (HPV4) covering HPV types $6 / 11 / 16 / 18$ is currently licensed for vaccination of 9-26 years old men.

Our findings should be interpreted in the context of the study design. Although our research scope was HPV prevalence, there are several limitations in this study. First, our cohort may not represent the entire population, as the studied patients already had a specific demand on HPV diagnosis prior to be referred to our laboratory. Therefore, a selection bias might be inferred since patients may represent a high risk population (e.g: previously treated for HPV, visible genital lesion or had a partner with diagnosed HPV). Moreover, our population was composed of a specific subset of the Brazilian population with full access to medical care. All patients were referred from private offices and had private medical insurance. Finally, in this study we could not study the epidemiology of the disease, including its transmission and potential influence of social and sexual habits on infection as well lack of follow-up data on each patient.

Future research should correlate these findings with women HPV prevalence. This correlation is of great importance considering the impact of the vaccination campaign as well as the transmission rate of the most prevalence HPV types found in our study.

\section{CONCLUSIONS}

This study demonstrates critical data on HPV prevalence and its subtype distribution among males with different age distribution. In our population, the most frequent HPV types were 6, 16, 42 and 51. Also, co-infection was found in almost $60 \%$ of our patients. In the future, this information should be useful to monitor the prevalence of vaccine-targeted HPV types after the introduction of vaccines.

\section{CONFLICT OF INTEREST}

None declared.

\section{REFERENCES}

1. Anic GM, Lee JH, Stockwell H, Rollison DE, Wu Y, Papenfuss MR, et al.: Incidence and human papillomavirus (HPV) type distribution of genital warts in a multinational cohort of men: the HPV in men study. J Infect Dis. 2011; 204: 1886-92.

2. Giuliano AR, Lee JH, Fulp W, Villa LL, Lazcano E, Papenfuss $M R$, et al.: Incidence and clearance of genital human papillomavirus infection in men (HIM): a cohort study. Lancet. 2011; 377: 932-40. Erratum in: Lancet. 2011; 377: 2006.

3. Giuliano AR, Anic G, Nyitray AG: Epidemiology and pathology of HPV disease in males. Gynecol Oncol. 2010; 117: S15-9.

4. Cranston RD: Anal cancer prevention: how we are failing men who have sex with men. Sex Transm Infect. 2008; 84: 417-9.

5. [No Authors]: Centers for Disease Control and Prevention (CDC): Human papillomavirus-associated cancers - United States, 2004-2008. MMWR Morb Mortal Wkly Rep. 2012; 61: 258-61.

6. Anic GM, Giuliano AR: Genital HPV infection and related lesions in men. Prev Med. 2011; 53(Suppl 1): S36-41. 
7. de Lima Rocha MG, Faria FL, Gonçalves L, Souza Mdo C Fernandes PÁ, Fernandes AP: Prevalence of DNA-HPV in male sexual partners of HPV-infected women and concordance of viral types in infected couples. PLoS One. 2012; 7: e40988.

8. Dunne EF, Markowitz LE: Genital human papillomavirus infection. Clin Infect Dis. 2006; 43: 624-9.

9. Wikström A, Hedblad MA, Syrjänen S: Penile intraepithelial neoplasia: histopathological evaluation, HPV typing, clinical presentation and treatment. J Eur Acad Dermatol Venereol. 2012; 26: 325-30.

10. Vaccarella S, Plummer M, Franceschi S, Gravitt P, Papenfuss M, Smith D, et al.: Clustering of human papillomavirus (HPV) types in the male genital tract: the HPV in men (HIM) study. J Infect Dis. 2011; 204: 1500-4.

11. Nyitray AG, da Silva RJ, Baggio ML, Lu B, Smith D, Abrahamsen M, et al:: The prevalence of genital HPV and factors associated with oncogenic HPV among men having sex with men and men having sexwith women and men: the HIM study. Sex Transm Dis. 2011; 38: 932-40.

12. Barzon L, Militello V, Pagni S, Franchin E, Dal Bello F, Mengoli C, et al.: Distribution of human papillomavirus types in the anogenital tract of females and males. J Med Virol. 2010; 82: 1424-30.

13. Shigehara K, Sasagawa T, Kawaguchi S, Kobori Y, Nakashima T, Shimamura M, et al.: Prevalence of human papillomavirus infection in the urinary tract of men with urethritis. Int J Urol. 2010; 17: 563-8.
14. Afonso LA, Moyses N, Alves G, Ornellas AA, Passos MR, Oliveira $\mathrm{Ldo} \mathrm{H}$, et al:: Prevalence of human papillomavirus and Epstein-Barr virus DNA in penile cancer cases from Brazil. Mem Inst Oswaldo Cruz. 2012; 107: 18-23.

15. Dunne EF, Nielson CM, Stone KM, Markowitz LE, Giuliano AR: Prevalence of HPV infection among men: A systematic review of the literature. J Infect Dis. 2006; 194: 1044-57.

16. de Lima SF Jr, Fernandes MC, Heráclio Sde A, de Souza PR, Maia Mde M: Prevalence of human papillomavirus genotypes: comparison between three detection methods in patients of Pernambuco, Brazil. Rev Bras Ginecol Obstet. 2011; 33: 315-20.

17. Castellsagué X, Iftner T, Roura E, Vidart JA, Kjaer SK, Bosch FX, Muñoz N, et al.: Prevalence and genotype distribution of human papillomavirus infection of the cervix in Spain: the CLEOPATRE study. J Med Virol. 2012; 84: 947-56.

18. Monsonego J: Genital infection with HPV in men: research into practice. Lancet. 2011; 377: 881-3.

Correspondence address: Marcos Paulo Freire, MD Rua Nova York 609 / 103B Sao Paulo, Brazil, 04560-001

Telephone: + 5511 7282-4508 E-mail: marcosfreire@grupofleury.com.br 